\title{
O DESENHO UNIVERSAL EM ESPAÇOS ABERTOS: UMA REFLEXÃO SOBRE O PROCESSO DE PROJETO
}

\author{
Universal Desing in Open Spaces: a Reflexion about Design \\ Process
}

\author{
Vanessa Goulart Dorneles', Sonia Afonso², Vera Helena Moro Bins Ely²
}

RESUMO Os espaços abertos são importantes elementos conectores e referenciais para as cidades, eles possibilitam a socialização, a prática de atividades de lazer, além de contribuir do ponto de vista ambiental para o meio urbano. Em função disto, estes espaços devem possibilitar sua apropriação por qualquer pessoa, independente de suas características físicas ou habilidades. O desenho universal é uma filosofia de projetos que visa auxiliar os projetistas a pensar na diversidade humana ao criar produtos, espaços e equipamentos, permitindo seu uso de forma independente e igualitária. Assim, neste artigo é apresentada uma reflexão de como o desenho universal pode estar presente durante o processo de projeto de espaços abertos. Neste artigo utilizou-se a definição de Gasperini (1988) que explica o processo de projeto baseado na trilogia: idéia, método e linguagem. Acredita-se que o desenho universal deva estar presente nestas três instâncias, ou seja, estar presente no lançamento inicial da proposta - a idéia, durante as etapas de concepção de projeto - o método, e na materialização final dos espaços - a linguagem.

PALAVRAS-CHAVE Desenho universal, espaços abertos, processo de projeto.

ABSTRACT The open spaces are important connectors and references elements to cities, they enable socialization, engaging in leisure activities, besides contribute to environmentally for the urban environment. Because of this, these spaces should allow its appropriation by anyone, regardless of their physical characteristics or abilities. To turn on these spaces inclusive is important that they are created considering the spatial needs of different users, i.e. that universal design can be present throughout the design process. The universal design philosophy is a project that aims to help designers to think of human diversity to create products, spaces and equipment, allowing its use independently and equally. So, this paper presents a reflection of how universal design can be present during the design process of open spaces. This paper used the definition of Gasperini (1988) explaining that the design process can be based on the trilogy: idea, method and language. It is believed that universal design should be present in these three instances, i.e. being present in the initial release of the proposal - the idea, during the design stages of the project - the method, and the final realization of the spaces - the language.

KEYWORDS Universal design, open spaces, design process. 


\section{INTRODUÇÃO}

Os espaços abertos são locais que propiciam às pessoas o contato com a natureza, a socialização e possibilidade de desenvolver atividades de lazer e esportes. Como estes espaços têm acesso livre e irrestrito, é importante que sejam inclusivos, permitindo que todas as pessoas, independente de suas características físicas e habilidades, possam usufruir de seus benefícios. Entretanto, para que estes espaços tornem-se inclusivos é preciso projetos que considerem o desenho universal.

O desenho universal é uma filosofia de projeto que tem por objetivo auxiliar arquitetos e designers a conceber projetos de produtos, espaços e meios de comunicações acessíveis à maior parcela da população possível, atendendo às suas necessidades (MACE; HARDIE; PLACE, 1996).

Sabe-se que todo projeto deve atender às necessidades dos seus diversos usuários, entretanto projetar considerando esta diversidade não é uma tarefa fácil. Certas estratégias de projeto que auxiliam uma parcela da população podem prejudicar outra. Encontrar projetos que conciliem grande parte destas necessidades ainda é muito raro, principalmente no Brasil.

Então, questiona-se: como aplicar o desenho universal durante o processo de projeto para tornar espaços abertos mais inclusivos?

Para responder a este questionamento é preciso, inicialmente, entender o conceito de desenho universal e seus desdobramentos, compreender como é o processo de projeto de arquitetura e, por último, explorar alternativas de como o desenho universal pode estar integrado a este processo.

O objetivo deste artigo é contribuir para a discussão sobre como projetar para todas as pessoas, independentemente de suas habilidades ou limitações.

Ao final do trabalho é possível retratar como seria a ideia, o método e a linguagem de projetos de espaços abertos com acesso universal.

\section{O DESENHO UNIVERSAL E OS ESPAÇOS ABERTOS}

O conhecimento das necessidades humanas para desenvolver projetos de arquitetura, urbanismo ou paisagismo não é apenas uma preocupação atual, pois até mesmo Vitruvius, em seus dez livros sobre a arquitetura, definiu a arquitetura em função de três princípios: venustas, fimirtas e utilitas (beleza, solidez e funcionalidade, respectivamente), correspondendo esta última à adequação do projeto às necessidades humanas (POLLIO, 2007).

Estas necessidades, relativas ao uso dos espaços, variam conforme as características físicas dos usuários e de suas habilidades. Sabe-se que uma pessoa com deficiência visual precisa de informações diferentes sobre o espaço do que as pessoas com boa acuidade visual, como, por exemplo, uso de informação tátil em pisos e mapas. Uma criança ou pessoa de baixa estatura em um píer com o guarda-corpo fechado até o chão, não consegue enxergar através do mesmo. Combinar as necessidades de todas as pessoas, para criar espaços inclusivos, é o objetivo do desenho universal. Este termo, que tem sido utilizado desde 1985, foi desenvolvido por Ronaldo Mace e outros pesquisadores para explicar um desenho de produtos e espaços adequados a todas as pessoas, independente de suas características físicas ou habilidades (CONNELL et al., 1997). A intenção do desenvolvimento deste termo era de suprimir a ideia de adaptação de espaços para pessoas com deficiência e proporcionar um conceito mais amplo de projeto, que não segregue nenhuma parcela da população, mas passe despercebido aos olhos dos usuários em geral. 
O termo desenho universal muitas vezes é entendido de forma similar ao termo acessibilidade ou desenho acessível; entretanto o primeiro tem um caráter mais abrangente e está relacionado com a concepção de projetos.

Acessibilidade significa prover um ambiente de condições mínimas para obtenção de informação/orientação sobre o espaço, de forma a permitir a interação entre usuários, o deslocamento e uso dos equipamentos e mobiliários com segurança e conforto (DISCHINGER; BINS ELY; PIARDI, 2009). Um desenho acessível pode ser destinado a indivíduos específicos ou grupos de indivíduos com limitações (ORMEROD; NEWTON, 2011), ou, ainda, pode ser um projeto adaptado a determinadas necessidades espaciais de usuários específicos, por exemplo.

Um desenho acessível também pode ser aquele que está de acordo com as normas de acessibilidade. No Brasil, a NBR9050/2004 representa um avanço em prol da inclusão social, pois apresenta parâmetros técnicos de projeto que garantem o mínimo de condições de acesso às pessoas com deficiência (ASSOCIAÇÃO..., 2004), entretanto a garantia destas condições mínimas não significa, necessariamente, a promoção de espaços inclusivos, que não segreguem e que propiciem conforto e segurança aos usuários. Neste sentido, o conceito de acessibilidade integral vai um pouco mais além, significa dar condições iguais às pessoas em qualquer contexto, considerando o conjunto onde o individuo está inserido, desde condições de acesso das edificações, do transporte, do espaço urbano, como também dos aspectos técnicos referentes aos mobiliários, pisos etc. (UBIERNA, 2006).

Como o conceito de desenho universal está baseado em princípios de igualdade para todos os indivíduos, sem discriminação, este artigo considera este termo mais apropriado quando se trata de concepção de projetos, uma vez que a filosofia do desenho universal não foca apenas do resultado final do artefato projetado, mas por permear todo o processo de projeto.

Vale ressaltar, portanto, que para o desenho universal ser efetivamente utilizado, arquitetos devem tê-lo em mente desde o início do projeto, e para isso é necessário conhecimento e compreensão aprofundados das necessidades espaciais das pessoas (HEYLIGHEN; BIANCHIN, 2010).

Hunt (1991) classifica as necessidades espaciais dos idosos em três categorias: físicas, informativas e sociais. Entretanto, estas três categorias não são exclusividade dos idosos pois, qualquer pessoa está sujeita a enfrentar tais necessidades. As necessidades físicas, por exemplo, estão relacionadas com a saúde física, segurança e com o conforto dos usuários no ambiente. Assim, um ambiente que atende a estas necessidades não possui obstáculos ou elementos que causem insegurança. As necessidades informativas estão relacionadas ao modo como a informação sobre o meio-ambiente é processada e, desta forma, o ambiente deve ser legível e permitir uma boa orientação espacial. Já, as necessidades sociais estão relacionadas com a promoção do controle da privacidade e/ou interação social, então um espaço agradável à permanência das pessoas e deve possibilitar opções de escolha em relação à privacidade.

Um bom projeto considera as necessidades espaciais, e desta forma os usuários podem se apropriar do espaço de forma independente, com segurança e conforto. Entretanto, projetar espaços levando em consideração todas estas necessidades não é uma tarefa fácil. O Center of Universal Design - CUD, na Carolina do Norte - Estados Unidos, procurou organizar os direcionamentos para projetar de forma inclusiva criando os sete princípios do desenho universal em 1997. Estes princípios podem ser aplicados em qualquer tipo de projeto, seja de ambientes, produtos e comunicações. Eles servem para guiar o processo de projeto, permitem uma avaliação sistemática 
Figura 1. Vista do anfiteatro ocupado pelos usuários. Fonte: (YOUNG; TRACHTMAN, 2000). do projeto e auxiliam na conscientização de projetistas e consumidores quanto às características de usabilidade das soluções de projeto (STORY, 2001).

Os sete princípios do Desenho Universal são descritos a seguir:

Princípio Um - Uso Equitativo: O desenho de espaços e equipamentos deve ser compreendido por pessoas com habilidades diversas, impedindo sua segregação ou estigmatização (CONNELL et al., 1997). Um bom exemplo deste princípio está presente no anfiteatro aberto da Bradford Woods Outdoor Center, da Universidade de Indiana (Figura 1 e 2). Como os bancos possuem assentos retráteis, uma pessoa em cadeira de rodas pode permanecer em qualquer posição do anfiteatro, e não apenas na parte inferior ou superior como é costume.
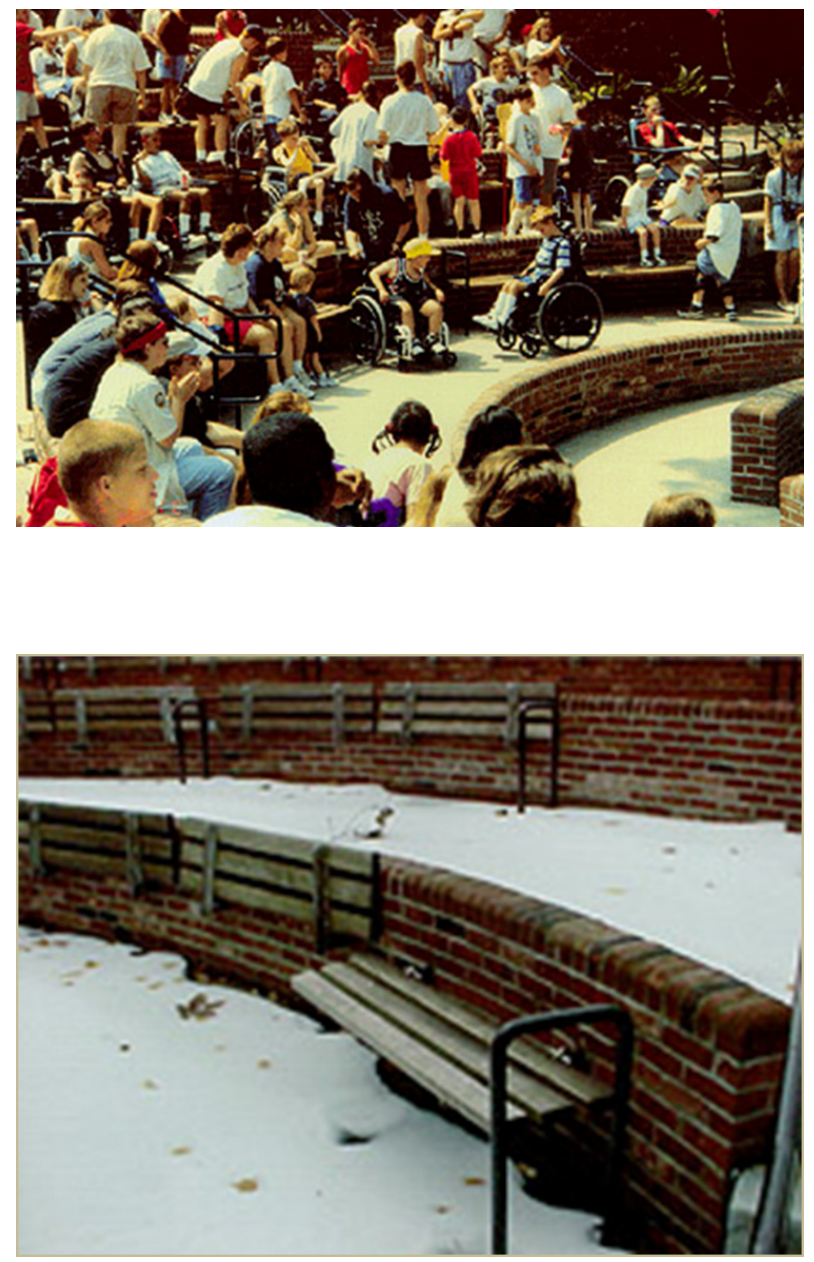

Figura 2. Detalhe do Banco retrátil no anfiteatro. Fonte: (YOUNG; TRACHTMAN, 2000).
Princípio Dois - Flexibilidade no Uso: As diversas preferências e habilidades individuais devem ser consideradas no desenho, possibilitando opção de escolha aos usuários conforme suas necessidades (CONNELL et al., 1997). Este princípio pode ser exemplificado com a Figura 3, que ilustra uma praça com desníveis que possui opções de circulação, com rampa e escada, conforme a escolha de cada usuário. $\mathrm{Na}$ imagem uma pessoa de bicicleta opta pela rampa para se deslocar.

Princípio Três - Uso Simples e Intuitivo: Os espaços e equipamentos devem ser de fácil compreensão, independente da experiência, conhecimento, habilidades de linguagem ou nível de concentração dos usuários (CONNELL et al., 1997). No Sensory Garden (Figura 4), em Osaka, no Japão, foram colocados pilares em todos os acessos como forma de marcar o início de caminhos importantes, facilitando a visualização dos mesmos por pessoas com baixa visão, pessoas que não conhecem o lugar ou pessoas com deficiência cognitiva.

Princípio Quatro - Informação de Fácil Percepção: O desenho comunica a informação necessária ao usuário, independente das condições do ambiente ou de suas habilidades (CONNELL et al., 1997). As informações sobre os espaços e as atividades devem ser fornecidas de diferentes maneiras, colaborando com pessoas com deficiência visual total e parcial, pessoas que não conhecem o local, turistas que não falam a língua do país, crianças, entre outros. Na Figura 5, os corrimãos apresentam informações em Braille indicando aonde o caminho vai levar. Na Figura 6, há um mapa com informações escritas e em Braille, um mapa em relevo e, também, um sistema de som com informações sobre o local.

Princípio Cinco - Tolerância ao Erro: O desenho minimiza riscos e consequências adversas de ações acidentais ou não intencionais (CONNELL et al., 1997). Por exemplo, no Rinku Park (Figura 7), em Osaka no 
Japão, foram colocadas guias por todo o parque indicando os caminhos mais seguros para circulação, sem obstáculos ou grandes inclinações.

Princípio Seis - Baixo Esforço Físico: O espaço ou equipamento deve ser eficiente e confortável na sua utilização, considerando todas as habilidades dos usuários, ocasionando-lhes o mínimo de fadiga(CONNELL et al., 1997). Por exemplo, no Jardim do Projeto Comunitário Alex Wilson no Canadá (Figura 8), o caminho principal possui uma mesma inclinação do começo ao fim, e foram escolhidos materiais estáveis para o piso, facilitando o percurso para os usuários (YOUNG; TRACHTMAN, 2000).

Princípio Sete - Dimensão e Espaço para Aproximação e Uso: Os espaços e os equipamentos devem ter dimensões apropriadas para o acesso, o alcance, a manipulação e o uso, independente do tamanho do corpo do usuário, da postura ou mobilidade (CONNELL et al., 1997). Exemplos interessantes deste princípio são elevações de espelhos d'água ou floreiras que permitem o contato de pessoas em cadeira de rodas, como acontece no Sensory Garden, em Osaka no Japão (Figura 9).

Como visto anteriormente, estes princípios não consistem em regras de como projetar ou parâmetros técnicos a serem cumpridos, mas sim um direcionamento de como pensar a ideia ou conceber os projetos considerando as necessidades espaciais das pessoas. Além disso, os exemplos demonstram que algumas estratégias de projeto podem e devem considerar mais de um princípio.

Além destes sete princípios é importante compreender o verdadeiro propósito do desenho universal que consiste em melhorar o desempenho humano, a saúde e a participação social para a maior gama possível de pessoas (STEINFELD; MAISEL, 2012).

Para tornar a forma de se projetar com desenho universal ainda mais compreensiva para os projetistas, Steinfeld e Maisel (2012) desenvolveram oito objetivos do desenho universal, são eles:

- Adaptação ao corpo (body fit): acomodar uma grande variedade de tamanhos corporais e habilidades;

- Conforto (confort): desenvolver atividades considerando os limites da função corporal;

- Conscientização (awareness): garantir que a informação essencial para o uso seja facilmente percebida;

- Entendimento (understanding): criar métodos de operação e utilização de forma intuitiva, clara e sem ambiguidade;

- Bem estar (wellness): contribuir com a promoção da saúde, evitando doenças e prevenindo ferimentos ou lesões;
Figura 3. Transposição de desnível no meio urbano com opção de rampa e escada, na cidade de Oslo na Noruega. Fonte: Autores.
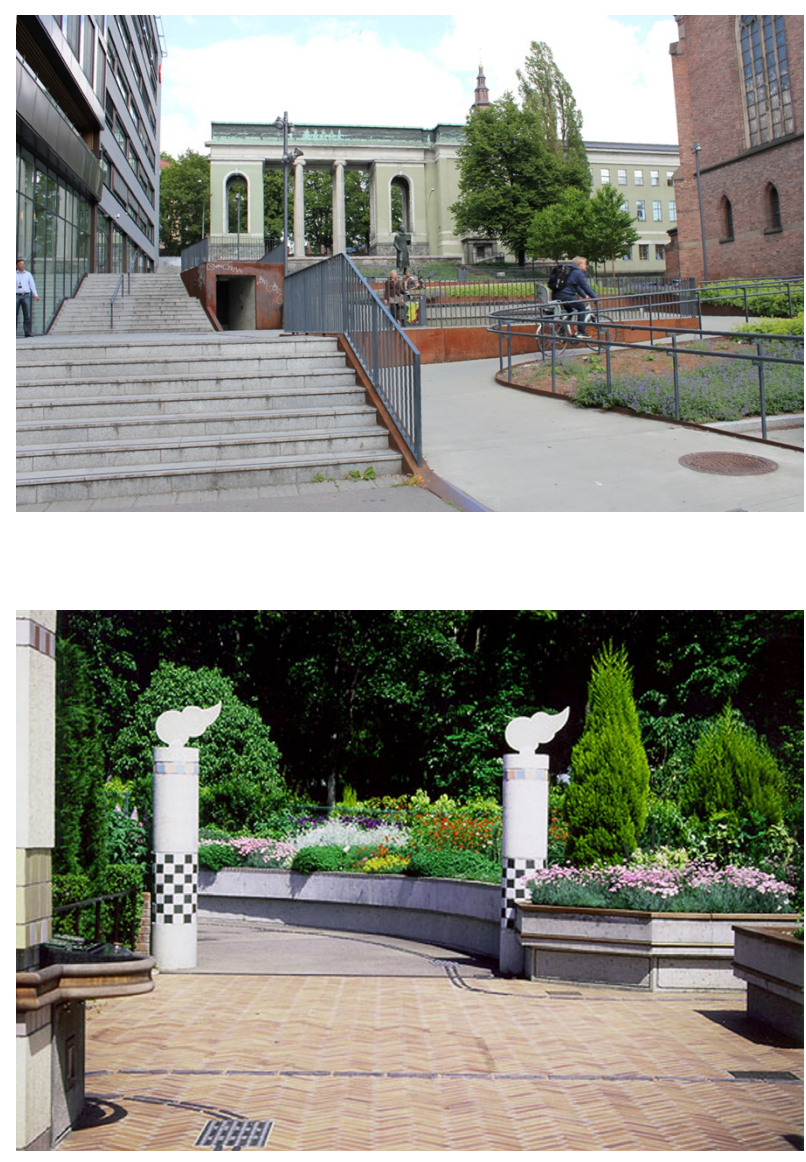

Figura 4. Presença de um par de pilares de orientação para marcar início de caminhos. Fonte: (YOUNG; TRACHTMAN, 2000). 
Figura 5. Informações táteis no corrimão. Fonte: (YOUNG; TRACHTMAN, 2000).

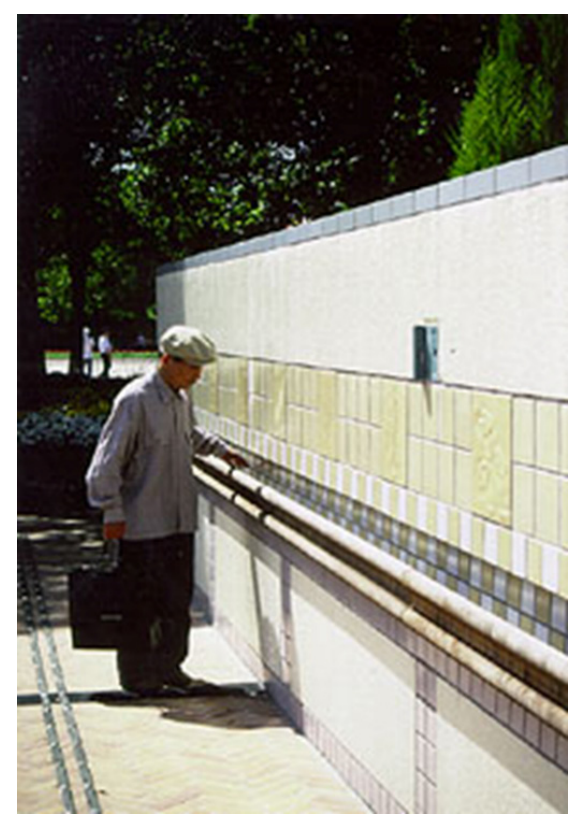

Figura 6. Mapa tátil, com informações escritas e em Braille, mapa em relevo e botão para sistema de som. Fonte: (YOUNG; TRACHTMAN, 2000).

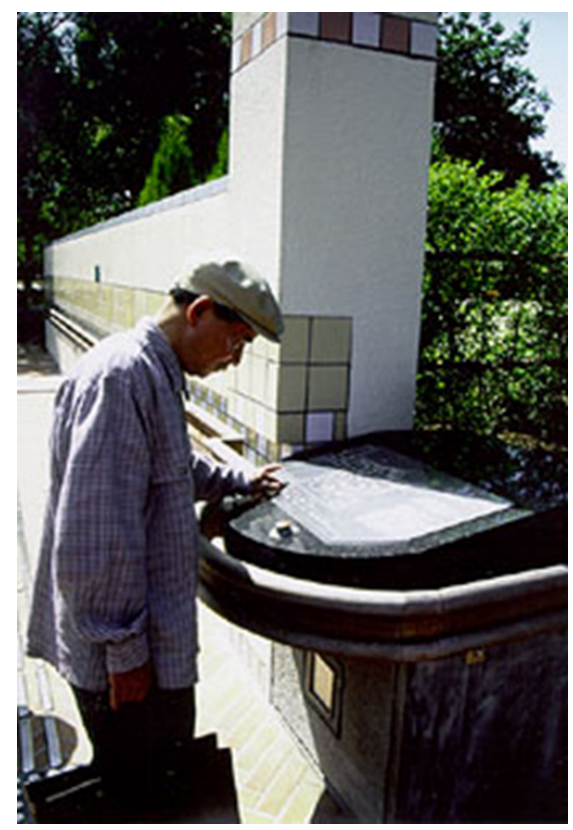

- Integração social (social integration): tratar todos os grupos com dignidade e respeito;

- Personalização (personalization): incorporar oportunidades de escolhas e expressões de preferências individuais;

- Adequação cultural (cultural appropriateness): incorporar e reforçar os valores culturais e o contexto ambiental e social em qualquer concepção de projeto.

A intenção destes oito objetivos é tornar o projeto de desenho universal mais palpável e até mesmo passível de verificação e avaliação.

Assim, os sete princípios, bem como os oito objetivos propostos por Steinfeld e Maisel (2012), auxiliam o projeto de qualquer espaço de forma universal e, conforme exemplos citados, podem ser aplicados aos espaços abertos com criatividade.

\section{PROCESSO DE PROJETO}

O projeto de arquitetura, urbanismo ou paisagismo, é a representação final de um determinado espaço concebido por arquitetos. Conforme Del Rio (1998), o significado da palavra projeto está relacionado a uma ação ou plano geral de trabalho, intenção de realizar algo, desígnio e iniciativa. Para este autor, elaborar um projeto depende de criatividade, capacidade de síntese, abstração, criação e de saber representá-lo.

Projetar é conceber soluções pela composição judiciosa dos elementos de arquitetura, concretizando-as em imagens que devem ser fixadas e comunicadas através de convenções gráficas, com concisão, precisão e elegância. [...] Ter ideias e saber concretizá-las: esse é o objetivo de quem projeta. (DEL RIO, 1998, p. 80).

Devido ao seu caráter criativo, muitos autores consideram difícil explicar como ocorre a concepção dos projetos. Esse modelo intuitivo de projeto é definido por Jones (1978) como uma caixa preta, cujo interior é desconhecido.

Entretanto, o processo de projeto de arquitetura pode ser descrito conforme as etapas do seu desenvolvimento, consistindo em um modelo mais racional ou a chamada caixa transparente (SILVA, 1986). Del Rio (1998) acredita que a criatividade pode auxiliar tanto na definição do partido geral, na resolução de problemas de conforto ambiental, quanto no levantamento de informações de projeto. Para ele, a organização do projeto em etapas resulta em uma maior compreensão e controle do papel do arquiteto ao longo de toda a projetação.

Para Gasperini (1988) o processo de projeto pode ser explicado a partir da trilogia: a ideia, o método e a linguagem adotados pelos arquitetos.

A ideia consiste no ponto de partida do projeto, onde o projetista reúne as informações necessárias e transforma em uma imagem mental. As ideias estão presentes no campo do 
processo cognitivo humano, da imaginação. Num projeto elas se caracterizam como decisões de projeto, conceito projetual ou resoluções de problemas. Conforme Afonso (1990), para alguns autores a ideia é considerada o mais importante em um projeto e está presente ao longo de todo o processo, para outros ela pode estar limitada a uma sequência de tarefas, e o principal fator de decisão é a análise.

O método projetual reflete o modo como é desenvolvido o projeto, desde sua concepção até sua materialização. É a forma como as ideias são organizadas e hierarquizadas, conforme cada contexto, e direcionadas para a confecção do produto final.

Conforme Gasperini (1988), mesmo que os arquitetos sigam uma mesma metodologia de projeto, suas soluções ou sínteses serão diferentes para cada temática, pois as decisões tomadas ao longo do percurso dependem do conhecimento específico de cada um, de sua experiência pessoal e da ordem de prioridades dada a cada fator interveniente. Por isso, cada projeto é único, pois cada projetista tem soluções impares para uma determinada problemática, mesmo que percorra um mesmo caminho.

\section{A linguagem em arquitetura} corresponde à forma de expressão do projeto, ou seja, a maneira como o arquiteto expõe suas ideias relativas a um determinado tema em um determinado contexto (GASPERINI, 1988). A linguagem também pode ser considerada como o caráter da arquitetura, o significado a ser interpretado da arquitetura no contexto das cidades, e neste caso, a arquitetura deve ser compreendida pelos seus usuários, e não apenas por quem constrói a obra.

A linguagem, portanto, é a arquitetura materializada, seus volumes, materiais, texturas e cores, tudo combinado de forma a acolher os usuários e permitir seu entendimento.

Vale ressaltar que a ideia, o método e a linguagem são aspectos indissociáveis no processo de projeto, separá-los consiste em um esforço metodológico e didático. Ao projetar essa separação conceitual não é sempre tão evidente.

\section{O PROCESSO DE PROJETO DE ESPAÇOS ABERTOS UNIVERSAIS}

Qualquer projeto de arquitetura considera os aspectos de forma, função, técnica e espaço para acomodar um

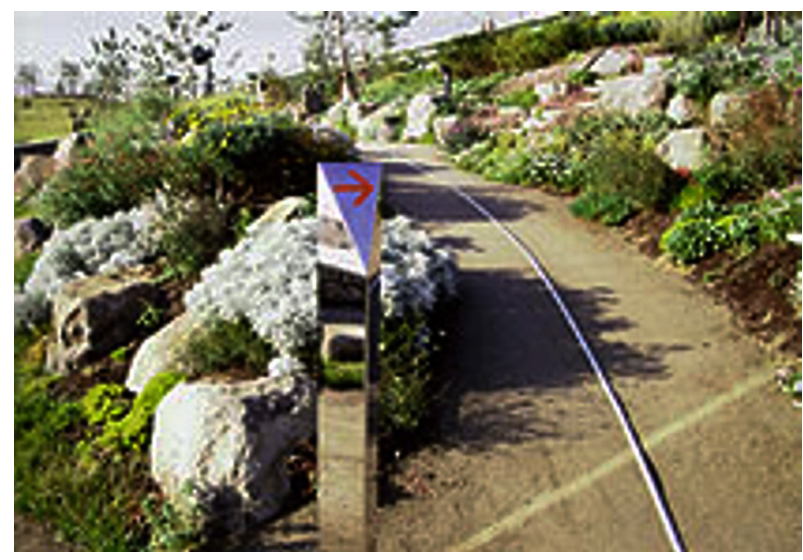

Figura 7. Guia de alumínio indicando o caminho

recomendável, ou seja, sem obstáculos ou desníveis. Rinku Park, em Osaka, no Japão. Fonte: (MIYAKE, 2001).

Figura 8. Caminhos do Jardim do Projeto Comunitário Alex Wilson, no Canadá. Fonte: (YOUNG; TRACHTMAN, 2000).

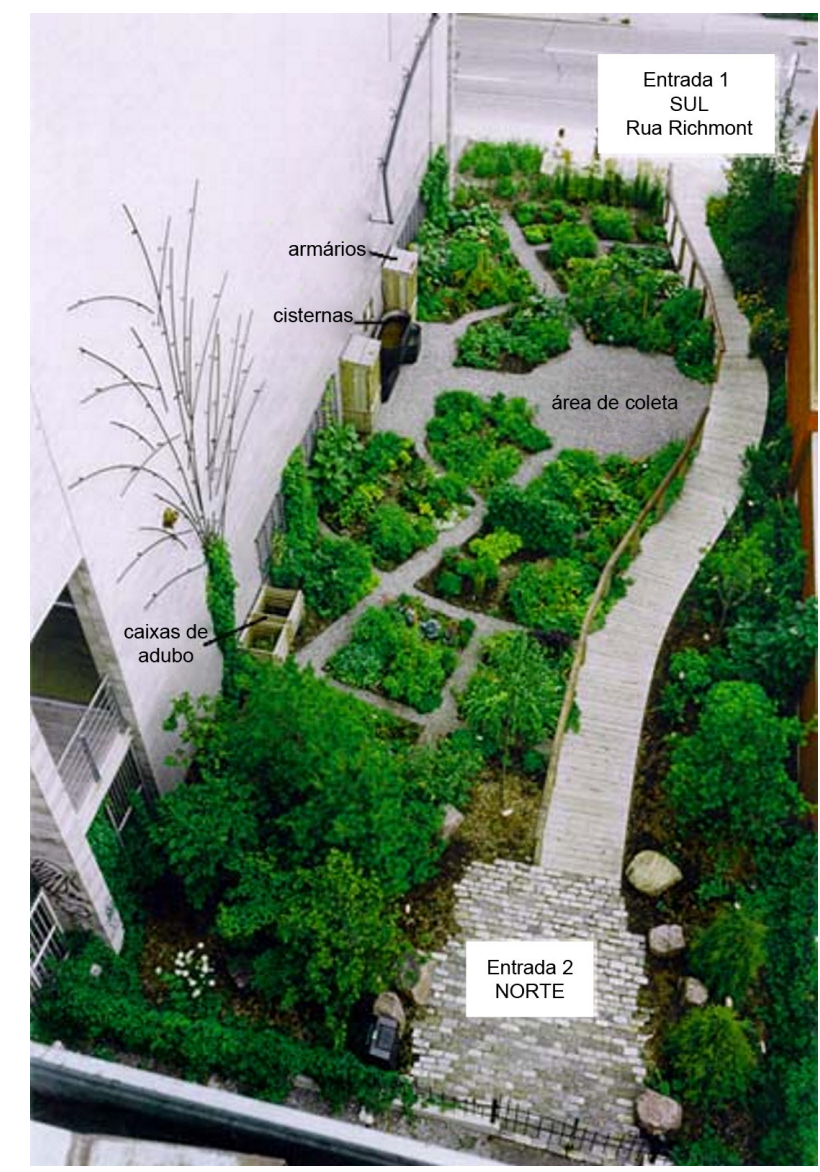




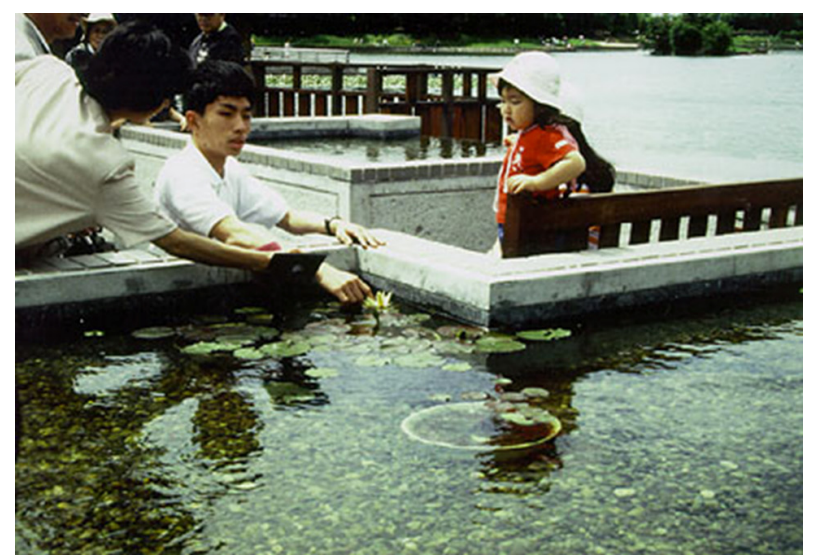

determinado programa arquitetônico, desde que seja compatível com o contexto (CHING, 1998). E todo o programa arquitetônico é voltado para o uso das pessoas e, sendo assim, deve procurar ser o mais inclusivo possível. O desenho universal busca auxiliar o desenvolvimento de projetos, para a maior gama possível de usuários, levando em conta sua funcionalidade sem desconsiderar seus aspectos estéticos. Assim, nesse artigo faz-se uma reflexão de como o conceito de desenho universal, seus princípios e objetivos podem permear toda a concepção projetual, ou seja, a ideia, o método e a linguagem da arquitetura.

Figura 9. Espaço com água elevado para alcance de pessoas em cadeira de rodas ou crianças. Sensory Garden, em Osaka, no Japão. Fonte: (MIYAKE, 2001).

\section{O DESENHO UNIVERSAL NA IDEIA DE PROJETO}

O desenho universal pode ser entendido como um conceito ou tema central, que está presente em todos os momentos de criação do projeto, tanto nas determinações gerais, como na implantação e definição do programa, quanto nas soluções mais pontuais e nos detalhes. O desenho universal auxilia a determinação das diretrizes de projeto, ou seja, as intenções e ideias que o projetista tem para o contexto no qual está trabalhando.

O princípio do uso equitativo, por exemplo, preconiza como conceber um projeto sem estigmatizar ou segregar ninguém, ou seja, proporcionar condições de acesso, deslocamento e uso dos ambientes de forma igual para todas as pessoas. Este princípio está relacionado com o objetivo de integração cultural proposto por Steinfeld e Maisel (2012), que visa exatamente integrar culturas, gêneros e idades, sem discriminação.

Sendo assim, para se pensar o desenho universal durante o projeto, é preciso ter como foco as necessidades espaciais dos usuários, considerando toda a sua diversidade. As necessidades espaciais dos usuários são todas as características do espaço arquitetônico ou paisagístico que possam contribuir para a participação das pessoas em qualquer atividade. Assim, para entender estas necessidades é preciso saber como as pessoas, com diferentes características e habilidades, compreendem o espaço, se comunicam umas com as outras, se deslocam ao longo dos percursos e usam os espaços e equipamentos (DISCHINGER; BINS ELY; BORGES, 2009). Com posse dessas informações, o projetista tem condições de propor soluções criativas e que possam ir além de especificações técnicas ou normativas.

Portanto, a fase de partido geral e programa arquitetônico devem incluir espaços e atividades adequados às necessidades dos usuários para atrair a população como um todo.

Um ambiente inclusivo é fruto de um projeto que utilizou os princípios do desenho universal desde a ideia inicial, pois desta forma o projeto não requer adaptações futuras ou revisões para adequações normativas.

\section{O DESENHO UNIVERSAL NO MÉTODO DE PROJETO}

Para fins deste artigo, o processo cognitivo de criação de um projeto de arquitetura foi simplificado em três fases distintas: Levantamento de dados e diagnóstico, Partido Geral ou Prognóstico, e detalhamento de soluções (Figura 10).

A primeira fase consiste num período mais exploratório onde o arquiteto busca informações necessárias para lançar as primeiras ideias. O período 


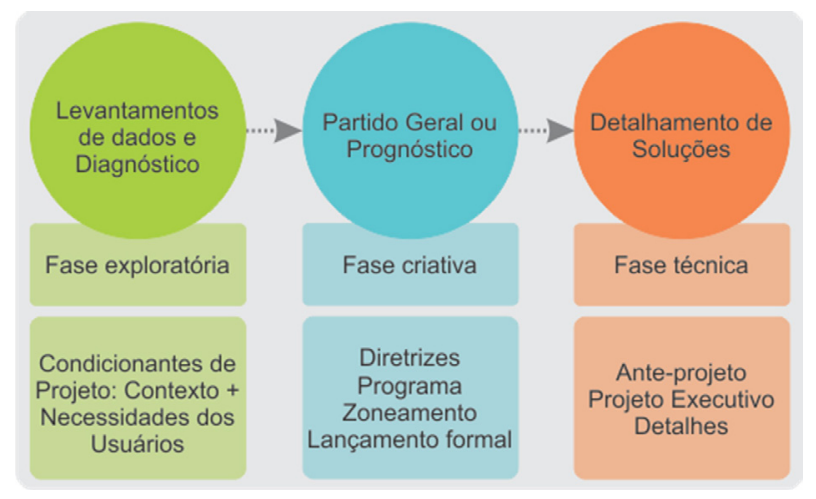

entre estas primeiras ideias até o lançamento formal e funcional consiste na segunda fase, mais criativa, que pode ser considerada como o Partido Geral ou Prognóstico. A última fase consiste numa etapa mais técnica, onde há um detalhamento das soluções de projeto e determinação de especificação de materiais.

Para que o projeto possa ser considerado inclusivo, a filosofia do desenho universal pode permear estas três fases.

Então, na primeira fase, onde são levantados todos os requisitos e condicionantes ao projeto, as necessidades espaciais dos usuários também devem ser investigadas. Para isto é importante ter em mente qual o público alvo que o projeto se destina e todos os demais usuários que poderão usufruir do espaço futuramente. Paulsson (2006), professor de arquitetura na Suécia, em seu livro sobre o ensino de desenho universal, destaca que para se projetar de forma inclusiva é necessária a experiência pessoal do projetista em relação às necessidades que as pessoas com limitações apresentam no uso dos espaços. Como na Suécia, as leis de inclusão foram implementadas há mais tempo, os arquitetos e alunos de arquitetura convivem com pessoas com alguma deficiência desde o ensino fundamental. Como no Brasil a consciência quanto às necessidades das pessoas com restrições é muito recente, as informações quanto às necessidades dos usuários podem ser buscadas através de métodos científicos, como entrevistas, passeios acompanhados (DISCHINGER, 2000) e observações de comportamento, e também através de bibliografias disponíveis sobre o assunto em livros, sites e cartilhas. Um exemplo da utilização de entrevistas para esta finalidade é desenvolvida por Miyake (2001) que procura fazer entrevistas com pessoas com alguma deficiência ou idosos, usuários de parques, para compreender suas necessidades. Ele já realizou cerca de 600 entrevistas que servem como banco de dados para os projetos de parques e praças que ele desenvolve.

Heylighen e Bianchin (2010) sugerem a cooperação entre designers e as pessoas para quem eles projetam, durante o desenvolvimento de projetos inclusivos, para conciliar as informações técnicas e pessoais da melhor forma possível. Esta cooperação pode ocorrer em forma de consultoria, no período de projeto, ou em forma de avaliação de satisfação, nos primeiros protótipos criados.

Na segunda fase, durante o Partido Geral, é possível converter as necessidades espaciais humanas em forma de diretrizes e soluções projetuais. Nesta etapa os princípios do desenho universal podem contribuir enquanto reflexão e ações de projeto. Por exemplo, a criação de espaços que sejam integradores, sem segregar nenhum usuário (princípio do uso equitativo), evitando acidentes (princípio da tolerância ao erro) e diminuindo equívocos
Figura 10. Ordem das fases de projeto. 


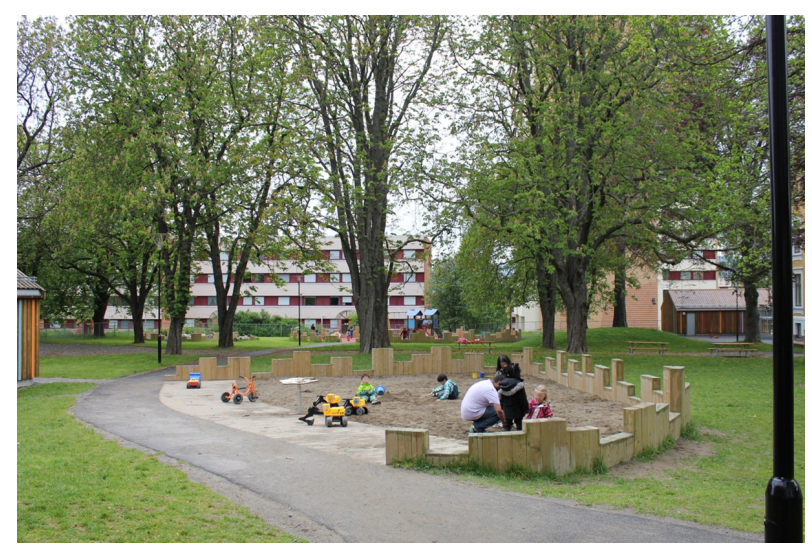

de orientação por parte dos usuários (princípio do uso simples e intuitivo) é uma forma que os princípios contribuem durante o lançamento do projeto.

Nesta etapa são definidas todas as atividades que as pessoas podem participar no espaço aberto. Criar espaços democráticos significa proporcionar oportunidades iguais, com opções de atividades para pessoas com diferentes características e habilidades. A Figura 11, ilustra um espaço democrático, o playground de uma creche na cidade de Oslo, onde todas as crianças podem brincar na areia igualmente, pois a cerquinha com diferentes alturas, ao redor da caixa de areia, permite a transferência das crianças

Figura 11. Playground da Creche Barneslottet, na cidade de Oslo. Foto Autoras. em cadeira de rodas de forma independente, conforme recomenda o princípio de desenho universal - baixo esforço físico. Este espaço é democrático pois não impede nenhuma criança de usar o playground com liberdade e segurança.

Na etapa de Detalhamento as soluções mais específicas são resolvidas, e para isto é necessário um amplo conhecimento técnico quanto ao uso de materiais e elementos urbanos. Os materiais de piso, por exemplo, devem ser estáveis, rígidos e preferencialmente antiderrapantes (DORNELES, 2006). Os materiais de revestimentos e cores utilizadas devem ter um padrão para evitar confusão visual, por exemplo, usar uma cor de piso de forma recorrente em todos os ambientes para crianças (BINS ELY; DORNELES; PAPALEO, 2008). A vegetação, além das funções ambientais e estéticas, pode ter função de orientação das pessoas com deficiência visual, pois ao exalar odores auxiliam como referencia para indicação de espaços específicos dentro das áreas abertos ou até mesmo de acesso (DORNELES; BINS ELY, 2006). Desta forma a vegetação funciona como uma informação adicional do ambiente, esta estratégia corrobora com o princípio de desenho universal - informação de fácil percepção.

Quando os mobiliários e equipamentos a serem implantados possibilitam opções de escolhas para os usuários está se projetando conforme o princípio da flexibilidade de uso. Por exemplo, os bancos com diferentes configurações (com e sem encosto, com e sem apoio para braços) e até mesmo diferentes alturas também correspondem a este princípio. Outro exemplo é a escolha de modelos de mobiliários simples e de fácil compreensão, sem complexidade de design, que corroboram com o princípio de uso simples e intuitivo do desenho universal.

\section{O DESENHO UNIVERSAL NA LINGUAGEM DE PROJETO}

A linguagem de um projeto inclusivo é simples, de fácil compreensão e com composições formais claras. A implantação dos materiais e texturas pode auxiliar na compreensão do espaço e na orientação dos usuários, seja pela marcação de pontos estratégicos, como acessos, seja pela definição de padrões de cores por setores funcionais, por exemplo.

O projeto de um espaço aberto, pensado para o uso de todas as pessoas, deve ter uma configuração espacial simples, evitando que as pessoas sintamse perdidas ou sem saber para onde ir, conforme indicado pelo princípio da informação de fácil percepção. Uma hierarquia clara de percursos, com distinção entre os caminhos principais e os secundários é uma forma de contribuir para esta orientação espacial. Além disso, se as atividades 
previstas no espaço aberto tem um zoneamento bem claro, e até mesmo uma setorização funcional, separando as áreas de maior movimento e agitação das áreas de descanso e contemplação, facilita a locomoção e o entendimento do espaço como um todo.

Outra forma de garantir uma boa orientação espacial é o uso de referenciais, como uso de vegetação com floração evidente, marcando os acessos, os cruzamentos ou os pontos de encontros, auxiliando na legibilidade do espaço (princípio do uso simples e intuitivo).

Para atender o objetivo de entendimento de espaços, as informações de seus usos e atividades podem ser transmitidas de diferentes maneiras como, por exemplo, por placas informativas, guias ou mapas, pela presença de informações táteis, pela padronização de cores por setor funcional, texturas e até mesmo pelo uso de composições homogêneas de vegetação que se repetem conforme a função do ambiente.

Além disso, uma linguagem que estimula os diferentes sistemas sensoriais com uso de elementos sonoros, táteis, visuais e olfativos para auxiliar na orientação espacial, na obtenção de informações sobre o ambiente, incentivando a exploração de novos cenários e novas experiências.

Em relação às questões físicas dos espaços, os objetivos de desenho universal - conforto e ao bem estar dos usuários - podem ser contemplados com uma definição de pisos e revestimentos em geral que possuem boa durabilidade e estabilidade, bem como, com a definição de mobiliários urbanos que sejam ergonomicamente adequados à população local.

Vale ressaltar, ainda, que espaços com uma boa integração, que não segregam, não passam despercebidos pelos usuários e não ficam sem apropriação. O projeto que primar pelo conforto e usabilidade dos ambientes e mobiliários pensa no bem estar de todos que é um dos objetivos do desenho universal.

\section{CONSIDERAÇÕES FINAIS}

Este artigo mostrou que o desenho universal, seus princípios e objetivos podem estar presentes no processo de projeto de espaços abertos, desde sua concepção até sua materialização. Entretanto, sabe-se que nem sempre os projetos são desenvolvidos com o foco nas necessidades dos seus usuários, podendo ter como prioridade aspectos estéticos ou econômicos.

Não é intenção deste trabalho desmerecer a concepção de projetos que visam a beleza estética ou a economia, mas sim, conscientizar os projetistas de que as questões de funcionalidade também são importantes. Um aspecto não exclui o outro, um bom projeto pode ser funcional, bonito e economicamente viável.

Assim, ao se projetar qualquer espaço é importante considerar as necessidades espaciais de seus usuários, independente de suas características físicas e habilidades. No caso dos espaços abertos, esta questão é ainda mais relevante, pois eles são espaços conectores da cidade e atraem todo o tipo de público.

O objetivo do desenho universal é contribuir com projetistas a desenvolver espaços acessíveis para todas as pessoas ou pelo menos para a maior parte delas. Conforme Bins Ely (2004, p. 20):

Para garantir a acessibilidade é necessário identificar os elementos que impedem ou restringem a percepção, compreensão, circulação ou apropriação por parte dos usuários dos espaços e atividades, bem como obstáculos de ordem social e psicológica que impedem seu uso efetivo. 
Entretanto, na segunda década do século XXI, o Brasil ainda enfrenta o desafio de conscientização, da sua população e de quem desenvolve os projetos arquitetônicos, paisagísticos e urbanísticos, da necessidade da inclusão de todas as pessoas. Para que o desenho universal seja disseminado entre os projetistas, em primeiro lugar, é importante que haja discussões teóricas de como projetar produtos e espaços para todos. E em segundo, as Universidades devem proporcionar aos alunos o contato com este tema e sua aplicação de forma prática, em disciplinas de projeto arquitetônico, de paisagismo e urbanismo.

Somente com profissionais capacitados para projetar espaços inclusivos e com a construção destes espaços é que a sociedade pode realmente entender a importância de garantir o direito de todos à participação nos espaços.

Neste artigo buscou-se relacionar o desenho universal no processo de projetos de espaços abertos, mas acredita-se que a abordagem exposta também pode ser estendida para outros espaços e ambientes.

Vale ressaltar, ainda, que esta discussão não está esgotada, é apenas uma reflexão de como contribuir com projetos de espaços abertos universais e incentivar a troca de informações e de experiências entre os profissionais da área.

\section{REFERÊNCIAS}

ASSOCIAÇÃO BRASILEIRA DE NORMAS TÉCNICAS - ABNT. NBR 9050/2004:

Norma Brasileira de Acessibilidade a edificações, mobiliário, espaço e equipamentos urbanos. Rio de Janeiro: ABNT, 2004.

AFONSO, S. Idéia, Método e Linguagem: Considerações a Respeito da Própria Experiência sobre o Tema. Revista de Arquitetura. Revista do Departamento de Arquitetura e Urbanismo da UFSC, Florianópolis, n. 2, p. 12-21, 1990. Texto apresentado na Disciplina ARQ827 - Projeto como Pesquisa Contemporânea. Síntese.

BINS ELY, V. H. M. Acessibilidade Espacial - Condição Necessária para o Projeto de Ambientes Inclusivos. In: DE MORAES, A. (Ed.). Ergodesign do Ambiente Construído e Habitado: Ambiente Urbano, Ambiente Público, Ambiente Laboral. Rio de Janeiro: iUsER, 2004. Acessibilidade Espacial - Condição Necessária para o Projeto de Ambientes Inclusivos.

BINS ELY, V. H. M.; DORNELES, V. G.; PAPALEO, M. K. Desenho Universal Aplicado ao Paisagismo: CD-ROM. Florianópolis: PetARQ/UFSC, 2008.

CHING, F. Arquitetura: forma, espaco e ordem. São Paulo: Martins Fontes, 1998.

CONNELL, B. R. et al. Universal Design Principles: The Center for Universal Design Environments and Products for All People. Raleigh: NC State University, The Center for Universal Design, 1997.
DEL RIO, V. (Org.). Arquitetura: pesquisa \& projeto. Rio de Janeiro: FAUUFRJ, 1998. (Coleção PROARQ).

DISCHINGER, M. Designing for all senses: accessible spaces for visually impaired citizens. 2000. Thesis (Doctor of Phiolosophy)-Chalmers University of Technology, Göteborg, 2000.

DISCHINGER, M.; BINS ELY, V. H. M.; PIARDI, S. M. D. G. Promovendo a acessibilidade nos edifícios públicos: Programa de Acessibilidade às Pessoas com Deficiência ou Mobilidade Reduzida nas Edificações de Uso Público. Florianópolis: Ministério Público de Santa Catarina, 2009.

DISCHINGER, M.; BINS ELY, V. H. M.; BORGES, M. M. F. C. Manual de Acessibilidade Espacial para Escolas: o direito à escola acessível! Brasília: Ministério da Educação, Secretaria de Educação Especial, 2009.

DORNELES, V. G. Acessibilidade para idosos em áreas livres públicas de lazer. 2006. Monografia (Graduação em Arquitetura e Urbanismo)Universidade Federal de Santa Catarina, Florianópolis, 2006.

DORNELES, V. G.; BINS ELY, V. H. M. Áreas livres acessíveis para idosos. Paisagem e Ambiente, São Paulo, v. 22, p. 299-308, 2006.

\section{GASPERINI, G. C. Contexto e}

Tecnologia: O projeto como Pesquisa Contemporânea em Arquitetura. São Paulo: FAUUSP, 1988. 
HEYLIGHEN, A.; BIANCHIN, M. Can crap design be inclusive? In: CAMBRIDGE WORKSHOP ON UNIVERSAL ACCESS AND ASSISTIVE TECHNOLOGY, 5., 2010, Cambridge. Proceedings...

Cambridge, 2010. p. 55-62.

HUNT, M. E. The design of supportive environments for older people:

Haworth Press. Congregate Housing for the elderly, 1991.

\section{JONES, J. Christopher Métodos de} diseño. Barcelona: Editorial Gustavo Gili S.A., 1978

MACE, R. L.; HARDIE, G. J.; PLACE, J. P. Accessible Environments: Toward Universal Design. Raleigh: Center for Universal Design, 1996.

MIYAKE, Y. Chapter 48. Landscape Design. In: PREISER, W. F. E.; OSTROFF,

E. (Ed.). Universal Design Handbook. New York: McGraw-Hill, 2001. chapt. 48. Landscape Design

ORMEROD, M.; NEWTON, R. Is your inclusive my exclusive?: Edinburgh College of Arq. Open Space: People Space 3. In: INTERNATIONAL CONFERENCE ON RESEARCH INTO INCLUSIVE OUTDOOR ENVIRONMENTS FOR ALL, 2011, Edinburgh. Proceedings... Edinburgh, 2011.

PAULSSON, J. Universal Design

Education. Gotenborg: EIDD Sverige \& NHR, 2006
POLLIO, V. Tratado de Arquitetura/

Vitrúvio. São Paulo: Martins

Fontes, 2007.

SILVA, E. Sobre a Renovação do

Conceito de Projeto Arquitetônico e sua Didática. In: COMAS, C. E. (Ed.). Projeto arquitetônico disciplina em crise, disciplina em renovação. São Paulo: Projeto, 1986. Sobre a Renovação do Conceito de Projeto Arquitetônico e sua Didática.

STEINFELD, E.; MAISEL, J. L.

Universal Design Creating Inclusive Environments. Hoboken: John Wiley \& Sons, Inc., 2012.

STORY, M. F. Principles of Universal Design. In: PREISER, W. F. E.; OSTROFF, E. (Ed.). Universal Design Handbook. New York: McGraw-Hill, 2001. chapt. 10.

\section{UBIERNA, J. A. J. Manual de}

Accesibilidad Integral: Guía para la aplicación del Código de Accesibilidad de Castilla-La Mancha. 2. ed. Madrid: Junta de Comunidades de Castilla-La Mancha, 2006.

YOUNG, L. C.; TRACHTMAN, L. H.

Universal Design Exemplars. 2000. CDROM. Disponível em: <http://www.ncsu. edu/project/design-projects/sites/cud/ content/TOC.html>.

Correspondência

Vanessa Goulart Dorneles, vgdorneles@yahoo.com.br

Sonia Afonso, soniaasweet@gmail.com

Vera Helena Moro Bins Ely, vera.binsely@gmail.com 